\title{
A Quality Function Deployment Approach Through Management and Technology Development
}

\author{
Chia Wei Lo, National Cheng Kung University, Taiwan \\ Ying Kai Liao, Nanhua University, Taiwan \\ Giang Nu To Truong, Nanhua University, Taiwan \\ Phuong Minh Binh Nguyen, Van Lang University, Vietnam \\ Wann Yih Wu, Nanhua University, Taiwan
}

\begin{abstract}
The corrugated paper industry is an indispensable industry, and it has been developing for more than 50 years. Hence, it is important for a firm to find its core competence, study effective business strategies, and form a long-term competitive advantage. However, few researchers focus on the harmonizing between the operational problems and solutions from customer and supplier angles. The purposes of this research are to analyze frequently encountered problems and to find appropriate solutions to upgrade production efficiency and business performance for the corrugated paper industry in Taiwan. This study mixes quality function deployment and analytic hierarchy process approaches to find some operational problems and provide the solutions based on experts' experience. The findings are projected to deliver some significant contributions: academically, by professionally conducting further theoretical validation and by adopting suitable strategies to fit the needs of customers.
\end{abstract}

\section{KEYWORDS}

Analytic Hierarchy Process, Corrugated Paper, Critical Incident Technique, House of Quality, Quality Function Deployment

\section{INTRODUCTION}

Paper is one of daily necessities tightly related to our lives in many forms, such as newspaper, notebook, bill, tissue, cardboard box, and so on. With the progress of technology, the function and application of paper is getting more and more extensive (Lin \& Zheng, 2017). In addition, the annual consumption of a piece of paper in a country not only represents a nation's industrial, economic, and cultural condition; but also determines an index of life standard (Dahal, Henderson \& Munn, 2013). Therefore, the rise and fall of the paper industry has become the vanguard index of developed countries. Recently, the paper industry in Taiwan has suffered from structural change of domestic industry; such as the rise of environmental protection consciousness, the migration of downstream industry, insufficient labors, saturated market, and other factors. These situations cause the paper manufacturing industry to face more competitions. Moreover, in the $21^{\text {st }}$ century, the paper manufacturing industry is facing unforeseen changes because the globalization of politics, economics, society, and technological power offer unstoppable competition trends. Besides some public paper companies, currently, there 
are still hundreds of small and medium scale paper companies in Taiwan. Normally, they are middlestream and down-stream paper processing companies with less information, R\&D capabilities, and lower prices to engage in price competition for each company, leading to vicious circles. Hence, the paper industry needs to adapt to the environmental changes to execute more effective policies, such as cost-effective and labor-effective policy and identify internal and external operational problems.

Paper is a consumer-dedicated product that considers the cost, quality, function and concerns about the safety, comfort, and usability in different locations (Gavrilescu, Puitel, Dutuc \& Craciun, 2012). Managers need to consider all of the factors above while trying to fulfill the needs of the customers. Under intensely competitive market circumstances, the corrugated paper industry is always endeavoring to streamline the organization to meet customer satisfaction and maintain a good relationship with business partners (Paryani, Masoudi \& Cudney, 2010). Therefore, it is critical to improve the relationship and find appropriate solutions for the frequently encountered problems when cooperating with business partners. Furthermore, under the premise of sustainable management, the paper industry has to figure out the appropriate solutions for various kinds of organizational, technological, and operational issues; then set up internal and external strategies to control the cost and maximize the profit of a company (Jauhar Pant \& Abraham, 2014). Quality Function Deployment (QFD) is an approach intended to service quality and product design. It aims to satisfy customers' needs and then translate them into the targeted design and quality assurance throughout the production process (Chan \& $\mathrm{Wu}, 2002)$. QFD is a well-known approach among companies to analyze the relationship between design requirements and customer requirements. The fundamental concern of QFD is the House of Quality (HOQ) (Temponi, Yen \& Tiao, 1999). According to HOQ, customers' needs can be transferred to engineer idea then integrate them into the part or components, characteristics, and the process operation.

Although QFD originated in the manufacturing industry, previous studies rarely used QFD to discuss the issue of the paper industry. Generally speaking, what customers in the paper industry need is good quality, low price, and precise delivery date. The quality and function deployment transforms customer's needs into product design needs. It uses HOQ to meet the demanded quality to provide a guiding principle for the enterprise executive or decision makers. The advantages of QFD can also be applied in the paper industry by listening to the Voice of Customer (VOC) after integrating the function need; reduction of design change; reduction of production and service cost; and reduction of product development period.

From management point of view, managers need to understand customers' needs and identify some solutions to provide qualified product and services to fit customers' needs. This study intends to verify the management problems from experts inside the company. Customer requirements are investigated through expert interview and Critical Incident Technique (CIT). When management problems and the customers' needs are all identified, then possible solutions to the problems to fulfill customers' needs will be proposed. Through an evaluation between problems and solutions, a relationship matrix can be identified. It is expected that using such triangle methods, customer's demands can be fully satisfied.

The paper industry is an indispensable business in the manufacturing industry. Its condition and tendency are usually influenced by the market and the customer's need. When domestic industries numerously emigrate from Taiwan to other countries, the paper demand is gradually decreasing. In addition, the raw material such as pulp and waste paper are controlled by international market, while domestic paper industries generally rely on importation. Hence, it is very tough for domestic paper industries to survive. In addition to the previously mentioned two exterior problems, the paper industry encounters some main interior operational problems need to be resolved or improved. With the engagement of technology improvement, the paper industry should reduce the production cost, improve productivity, and use E-management to obtain more management efficiency (Civi, 2000). As a matter of fact, there are various processing procedures for paper-making manufacturer; therefore, it is better for a paper-making manufacturer to diversify its production on different processes to reduce the business 
risks (Amihud \& Lev, 1981). It is crucial for a company to increase productivity, enhance a company's competitiveness relative to its competitors, and raise a company's profitability. Generally, a company will improve productivity by modernizing and upgrading production facilities; engaging mergers and acquisitions to generate synergies; and changing the organization for better management (Ghosal \& Nair-Reichert, 2009). In addition, it is also significant for a company to modernize its production and management system to improve performance and efficiency. Nowadays, most machines in the paper industry are controlled by computers; the main goal is to improve its quality and productivity, reduce its production costs, and break through the environmental constraints (Dumont, 1986). Furthermore, all industries must have experienced some operational failures or problems, especially in this dynamic environment. The problems can be caused by inadequate equipment maintenance, inspection, repair, and coordination problems which arise among or between employees, management, and customers (Adler-Milstein, Singer, \& Toffel, 2009). As a consequences, the company may get low quality of product or service, because operational problems can distract employees in value-adding activities, weakening discipline process, and harm employees and customer directly (Tucker, 2004); further, it also influences organization's financial performance. Thus, understanding the company's operational problems is crucial to prevent it from causing bad outcomes for the company.

Because there are many operational problems in the paper industry, this study aims to identify the types of problems and divide them into different aspects according to the company's departments. This study intends to explore which solution is the most critical to customers. The main objectives of this research are to find the appropriate solutions for the frequently encountered operational problems during companies' cooperation with their suppliers and business partners. Based on the study background, this research combines the QFD and AHP method to help the corrugated paper industry's manager finding the best way to solve operational problems; then plan, organize, lead, and control a standard corporate structure. The outcome can help managers know how to improve the defect for each department to generate other synergies.

\section{LITERATURE REVIEW}

The inadequate equipment maintenance, inspection, repair, and coordination problems rised among employees, management, and customers may cause operational problems (Adler-Milstein et al., 2009). According to Tucker (2004), operational failures or problems are defined as the extent to which employees do not have supplies, equipment, information, or people needed to complete their work assignments. In more details, operational problems are related to the materials, equipment, help from others, tools, suppliers, budgetary support, information, and aspects of the work environment (Gilboa, Shirom, Fried \& Cooper, 2008). Therefore, in this paper, operational problems are categorized as production, marketing, human resource, research and development (R\&D) and financial problems.

Following Hou (2009), flaws caused by the product quality can be categorized into paper dimension issues or paperweight, paper surface issues, paper quality issues, and its negative effects on consumers. Paperweight deficiencies consist of error in paper weight and size, paper side cutting, datum and bending the line, and unstable paper weight. While paper strength problems consist of insufficient hardness, unstable moisture paper, deficiency form paper join, paper snap, no paper joint, paper snap due to its damaged paper sides, imperfect paper rewind, paper wrinkle, and paper strength (Figueira, Santos \& Almada-Lobo, 2013). Moreover, paper surface problems include the impurities from small pieces of rubber, plastics, and rubbish; paper color not stable or dye permeating effect; deficiency in the smoothness of paper skin; deficiency in the quality of printing; errors in the paper's waterproof capability; and deficiency from the intensity of flatness. In addition, other problems related to paper quality contain peculiar smell, unstable paper quality, and deficiency from stapling.

In general, marketing problems occur when organizations do not prioritize their users (Keller, 2017). If it happens, organization may not be able to grasp the real customer needs. Besides, bad channels selection and inconsistency cross-channels also create a problem in marketing because the 
organization may make a mistake in selecting a channel for certain customers; thus, the information regarding the product or service could not reach them. Furthermore, other problems related to the mechanism of marketing, such as internet, telephone, fax machines, may also inhibit the marketing process when those factors are inappropriately used (Kjellberg, Azimont \& Reid, 2015).

Human resource is essential in the organization, especially when it is human capital oriented. However, according to Howe-Walsh and Schyns (2010), there are crucial challenges inherent in human resources decision-making which involve intangible characteristics of human capital. Human behavior is difficult to predict, observe, and measure; thus the organizations are forced to put more effort in selecting the right human resources and managing their investment. When organizations make wrong decision by choosing low skilled- and low experienced-employees, they may need to spend more investment training them. Thus, recruiting the right person in the right position is very important for human management.

According to Huan, Yongyuan, Sheng and Qinchao (2017), problem in R\&D department usually caused by the typical cultural traits influences the way R\&D department assimilates the knowledge from various resources. Besides, R\&D scientists may also be reluctant to share their knowledge for fear that it is shared to to the wrong person or cannot be accepted by others. When the R\&D department faces this kind of problems, they may not be able to create a valuable or varied product and service for customers.

There are many measurements to measure the financial condition of the organization, such as through financial ratios of the organization. For instance, when the turnover rate ratio is low, the organization may face difficulties getting cash; thus, further influencing their operational activities, such as production and marketing. Besides, when the raw materials are getting more expensive while it does not possess enough financial capital, it inhibits the production activities. In this case, organization may decide to borrow money from the bank, however, it may be difficult for them to pay back if the load rate is too high. Therefore, it is better for organizations to find some ways in order to prevent it to happen.

\section{RESEARCH DESIGN AND METHODOLOGY}

\section{Research Methodology}

A complete and precise understanding of customer needs and expectations is the key to possess competitive advantage in the marketplace and stand out from an intensely competitive business environment (Pakdil, Işı, \& Genç, 2012). As an important management tool, QFD only offers a visual connective process to assist an organization in satisfying its consumer needs through product design and development cycle and contributes to increase customer satisfaction and decrease product design and development time (Stirn, 2006).

In this study, the following procedures are conducted:

Step 1: Prioritize Alternatives. A team of experts identified to express their opinions regarding the operational problems of a paper company using AHP methodology. This study identifies the following operational problems in the beginning stage of research; (1) production; (2) marketing; (3) human resources; (4) research and development; and (5) finance.

Step 2: Problem Solutions. Through the application of QFD, the operational problems are transferred to the needs which point it out into functional solutions. This study also intends to identify specific solutions to match the operational problems above. Specifically, the solutions including; Implemented logistics management system (A1); Put TQM into practice (A2); Eliminate old machines to upgrade production efficiency (A3); Implement ERP electronic system (A4); Increase customers' satisfaction (A5); Increase advertisement and marketing activity (A6); Develop different qualities of papers to meet the market's demand (A7); Upgrade service quality (A8); 

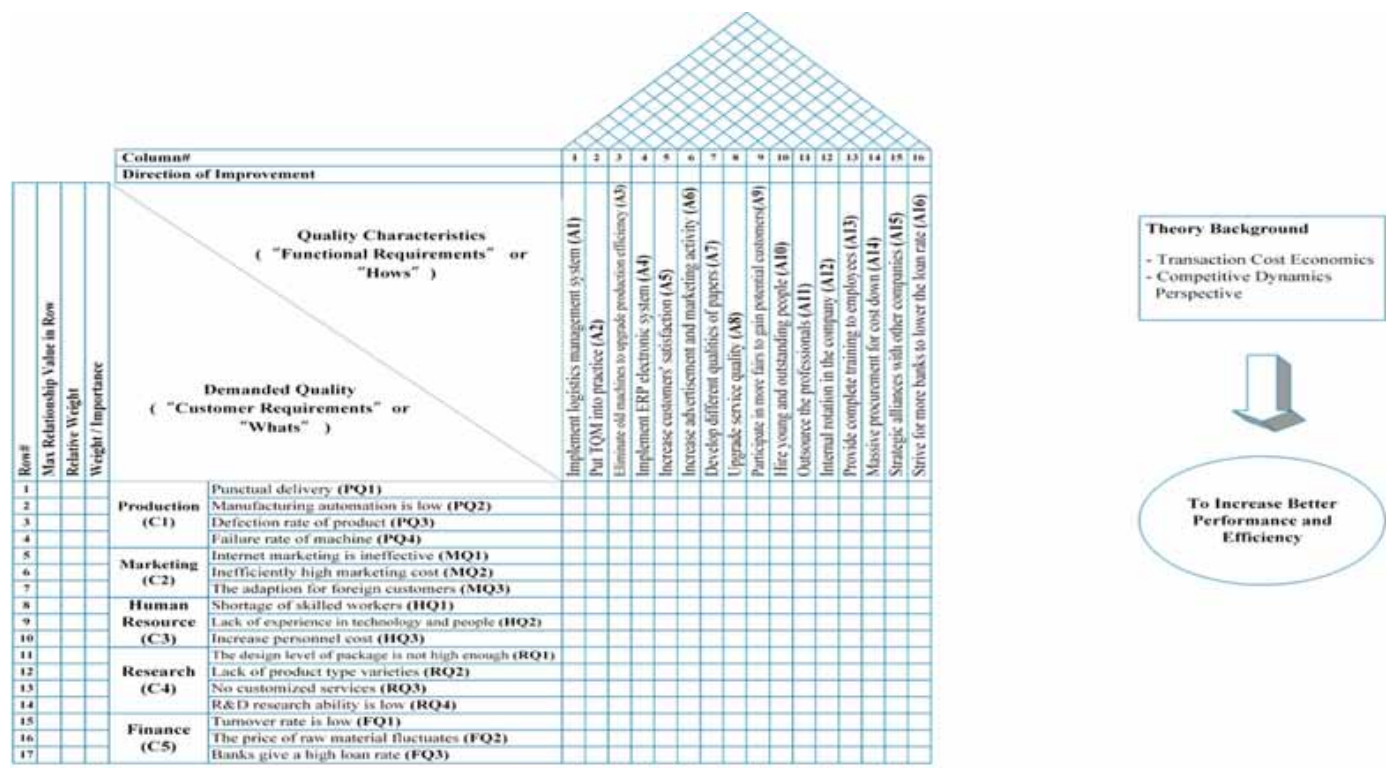

Participate at more fairs to gain more potential customers (A9); Hire young and outstanding people (A10); Outsource other professional companies (A11); Internal rotation of company to cultivate well-rounded employees (A12); Provide complete training to upgrade employees' techniques (A13); Massive procurement for cost down (A14); Strategic alliances with other companies (A15); and Strive for more banks to lower their loan rate (A16), are illustrated. Three levels of correlation between operational problems and solutions are established, namely: 9 (strong relationship), 3 (medium relationship), and 1 (week relationship). If there is no connection between problems and solutions, the matrix's correspondent crossings are left empty.

Step 3: Correlations among solutions. To identify the roof of HOQ, two solutions are deemed as correlated. If the variation of the value of one solution changes, the value of the other solution will also change, and vice versa. Positive correlation means that there is positive change simultaneously, while negative correlation means otherwise. It has become the relationship matrix or the roof of HOQ.

\section{Data Collection}

\section{CIT Interview Design}

The Critical Incident Technique (CIT) is a method for qualitative research and it specifically designs its procedures to observe human behavior to facilitate the researchers in classifying and generalizing problems more efficiently (Brunton \& Jeffrey, 2010). It is an effective approach to help companies improving their internal and external factors; the study applies this approach in the Taiwanese paper industry. Specifically, in order to find out the details of operational problems and the best solutions to solve them, this study conducts CIT for the experts as the beginning step.

Two Taiwanese sales representatives were interviewed to provide more professional and experienced opinions and viewpoints for the questionnaire items of this study. First of all, the company information questions including the scale, capital, number of employee, job position, and working experience were asked in the first part. Secondly, personal data questions, such as education level, age, monthly income, gender, and occupation were also looked into. Thirdly, the questions as 
previously mentioned and displayed in the Figure 1 were included in the questionnaire. Experts were asked to share their opinions related to the operational problems and the way they solve it. Fourthly, there are two types of different cross comparisons of each dimension for the structural study. Finally, experts were asked to explain which solution influences or is influenced by other; in other words, the correlation among solutions. These information was adopted to develop the questionnaire for AHP in the next section.

\section{AHP Questionnaire Design}

This study targets to explore the best solutions for a company to improve the cooperation with its partners to achieve better performance. AHP is a decision-making method to organize and analyze complicated decisions. It can be applied for general decision operation and group decision-making by decomposing a complicated problem into a multi-ranking hierarchical configuration of criteria, alternatives, and objectives (Sharma, Moon \& Bae, 2008). The questionnaire was designed in two parts. The first part explains how to fill the survey and asks respondents to fill in some basic companies and personal information. The second part is a paired comparison questionnaire. The scale varies from 1 to 9 with odd numbers as shown in the Table 1 .

Table 1. The Fundamental Scale Explanation of AHP Method

\begin{tabular}{|l|c|}
\hline \multicolumn{1}{|c|}{ Number } & Meaning \\
\hline 1 & Equal (two elements are the same importance with respect to the third one) \\
\hline 3 & $\begin{array}{c}\text { Moderate (slightly much) (one elements has a little more importance than the other with respect } \\
\text { to the third one) }\end{array}$ \\
\hline 5 & Much (one element has much more importance than the other one) \\
\hline 7 & Very much (one element is significantly more important than the other one) \\
\hline 9 & Extreme (one element is absolutely more important than the other one) \\
\hline
\end{tabular}

Thirty interviewees were invited to recall the most impressive case during their work in the past six months. The interviewers then had to find the detailed information and critical factor resulting from those situations based on interviewees' viewpoints. Afterward, the interviewers need to clarify the cause and effect. In addition to two sales representative experts, these thirty interviewees can also identify additional problems and solutions. The questionnaire design is basically divided into four parts, including the fundamental framework, explanation and example, questions, and respondent information. There are 16 actions in the horizontal line and 20 questions in the vertical line. Comparing with other studies' questionnaires, the conceptual model is complicated; thus, the respondents have to be careful to fill in the questionnaire. The questions are selected to evaluate the interviewees based on the observation of the study. In this study, those interviewees include experts in the paper industry from top managers to employees. The goal is to determine and further identify the Taiwan paper industry operational problems and the appropriate solutions to increase each department's performance and efficiency in the paper industry.

\section{FINDINGS}

\section{Respondent Information}

By using CIT method in the first stage, this study conducted 30 experts who have experienced in facing operational problems in the paper industry in Taiwan through interviews and open-ended 
questionnaire. Table 2 shows the detailed information about the interviewees. The interviewees are working in various management positions within the paper industry. Most of these interviewees are experienced; hence, they are able to provide useful ideas and information.

Table 2. The Information of Interviewees for AHP

\begin{tabular}{|c|c|c|c|}
\hline Number & $\underline{\text { Seniority }}$ & Title & User of the Experts \\
\hline$\underline{1}$ & $\underline{33 \text { years }}$ & Chairman & Industry Paper Product \\
\hline$\underline{2}$ & 24 years & $\underline{\mathrm{CEO}}$ & Industry Paper Product \\
\hline$\underline{3}$ & 22 years & Production Manager & Industry Paper Product \\
\hline 4 & 3 years & Finance Manager & Industry Paper Product \\
\hline$\underline{5}$ & 5 years & CEO & Industry Paper Product \\
\hline$\underline{6}$ & 7 years & CEO & Industry Paper Product \\
\hline$\underline{7}$ & 10 years & $\underline{\mathrm{CEO}}$ & Paper Broker \\
\hline$\underline{8}$ & 1 year & $\underline{\text { Art Design }}$ & Paper Broker \\
\hline 9 & 23 years & $\underline{\text { Sales Assistant }}$ & Industry Paper Product \\
\hline$\underline{10}$ & $\underline{27 \text { years }}$ & Finance Manager & Industry Paper Product \\
\hline$\underline{11}$ & 27 years & $\underline{\mathrm{CFO}}$ & Industry Paper Product \\
\hline$\underline{12}$ & 3 years & $\underline{\text { Sales Representative }}$ & Industry Paper Product \\
\hline$\underline{13}$ & 6 years & $\underline{\text { Sales Representative }}$ & Material Supplier \\
\hline$\underline{14}$ & 5 years & Production Manager & Material Supplier \\
\hline$\underline{15}$ & 2 years & $\underline{\text { Sales Representative }}$ & Material Supplier \\
\hline$\underline{16}$ & 6 years & $\underline{\text { Sales Representative }}$ & Material Supplier \\
\hline$\underline{17}$ & 3 years & QC Manager & Material Supplier \\
\hline$\underline{18}$ & 17 years & Sales Representative & Material Supplier \\
\hline$\underline{19}$ & 20 years & Sales Manager & Material Supplier \\
\hline$\underline{20}$ & 2 years & Sales Manager & Material Supplier \\
\hline$\underline{21}$ & 20 years & CEO & Material Supplier \\
\hline$\underline{22}$ & 18 years & Production Manager & Material Supplier \\
\hline$\underline{23}$ & 10 years & Marketing Manager & Material Supplier \\
\hline$\underline{24}$ & 10 years & HR Manager & Material Supplier \\
\hline$\underline{25}$ & 20 years & $\mathrm{CFO}$ & Material Supplier \\
\hline$\underline{26}$ & 12 years & Finance Manager & Material Supplier \\
\hline$\underline{27}$ & 10 years & Sales Representative & Material Supplier \\
\hline$\underline{28}$ & 5 years & $\underline{\text { Sales Assistant }}$ & Material Supplier \\
\hline$\underline{29}$ & 3 years & QC Assistant & Material Supplier \\
\hline$\underline{30}$ & 2 years & Production Assistant & Material Supplier \\
\hline
\end{tabular}


Table 3. Comparison Matrix and Weight of overall Operational Problem

\begin{tabular}{|c|c|c|c|c|c|c|}
\hline Goal & $\begin{array}{l}\text { Production } \\
\text { (C1) }\end{array}$ & $\begin{array}{l}\text { Marketing } \\
\text { (C2) }\end{array}$ & $\begin{array}{l}\text { Human } \\
\text { Resource } \\
\text { (C3) }\end{array}$ & $\begin{array}{l}\text { Research } \\
\text { (C4) }\end{array}$ & $\begin{array}{l}\text { Finance } \\
\text { (C5) }\end{array}$ & $\mathbf{e v}_{11}$ \\
\hline Production $(\mathrm{C} 1)$ & 1 & 7 & 7 & 5 & 7 & $0.610(\mathrm{EP})$ \\
\hline Marketing (C2) & $1 / 7$ & 1 & 1 & 1 & 1 & $0.092(\mathrm{EM})$ \\
\hline Human Resource (C3) & $1 / 7$ & 1 & 1 & 1 & 1 & $0.092(\mathrm{EH})$ \\
\hline $\mathrm{R} \& \mathrm{D}(\mathrm{C} 4)$ & $1 / 5$ & 1 & 1 & 1 & $1 / 3$ & $0.083(\mathrm{ER})$ \\
\hline \multirow[t]{2}{*}{ Finance (C5) } & $1 / 7$ & 1 & 1 & 3 & 1 & $0.124(\mathrm{EF})$ \\
\hline & $1.628(\mathrm{SP})$ & $11(\mathrm{SM})$ & $11(\mathrm{SH})$ & $11(\mathrm{SR})$ & $10.333(\mathrm{SF})$ & \\
\hline
\end{tabular}

$\lambda_{\max }=5.197 ; C R=0.044$

\section{QFD and AHP Computation}

Thirty experts were interviewed to provide relative importance between on elements and others based on AHP questionnaire. The result of these pairwise comparisons and eigenvector of the overall operational problems were calculated. The consistency ratios $(\mathrm{CR})$ were also calculated based on Saaty (2004). With the CR values of 0.001 for operations, 0.070 for marketing, 0.001 for human resource, 0.057 for $\mathrm{R} \& \mathrm{D}$, and 0.040 for finance, which are all lower than 0.1 , it can be concluded that the answers among experts are consistent.

In summary, the important rating of group (departments) and sub-groups (operational problems) are shown in Figure 2 below. Figure 2 shows that the problems in "Production" department is the most important problem to be solved, followed by problems in "Finance", "Marketing", "Human Resource", and "Research" department. Meanwhile, in sub-criteria, the most important problem in each department are as follows: "Punctual deliver" in "Production" department; "The price of raw material fluctuates" in "Finance" department; "The adoption for foreign customer" in "Marketing" department, "Shortage of skilled workers" in "Human Resource" department, and "The design level of package is not high enough" in "Research" department.

\section{The Co-Relationship Among Operational Action For Solutions}

At the roof of $\mathrm{HOQ}$, the relationship among action for solutions is determined. This part is important because management needs to consider the casual effect when doing the actions, since it can be positive or negative relationship. Positive relationship indicates that when one of the action is being used, other action can be used in the same way. Meanwhile, negative relationship means if an action is used, other action will be used in the opposite way. The roof part of HOQ is shown in Figure 3. Figure 3 shows that all of the inter-relationship among actions for solutions are positive. For example, when a company does the action of implement logistics management (A1), it also need to do other actions which are put TQM into practice (A2), eliminate old machines to upgrade production efficiency (A3), implement ERP electronic system (A4), increase customers' satisfaction (A5), upgrade service quality (A8), participate more fairs to explore more customers (A9), and outsource other professional companies (A11).

\section{The Relationship Matrix}

In this study, the correlation between customer requirements which is operational problems and technical requirements which is the action for solutions, were counted into different levels: 9 (strong relationship-¥), 5 (medium relationship- $i$ ), 1 (weak relationship- $\triangle$ ), and 0 (no relationship). Based on the knowledge of experts, the level of each correlation is decided. Figure 4 shows the matrix between 
Figure 2.

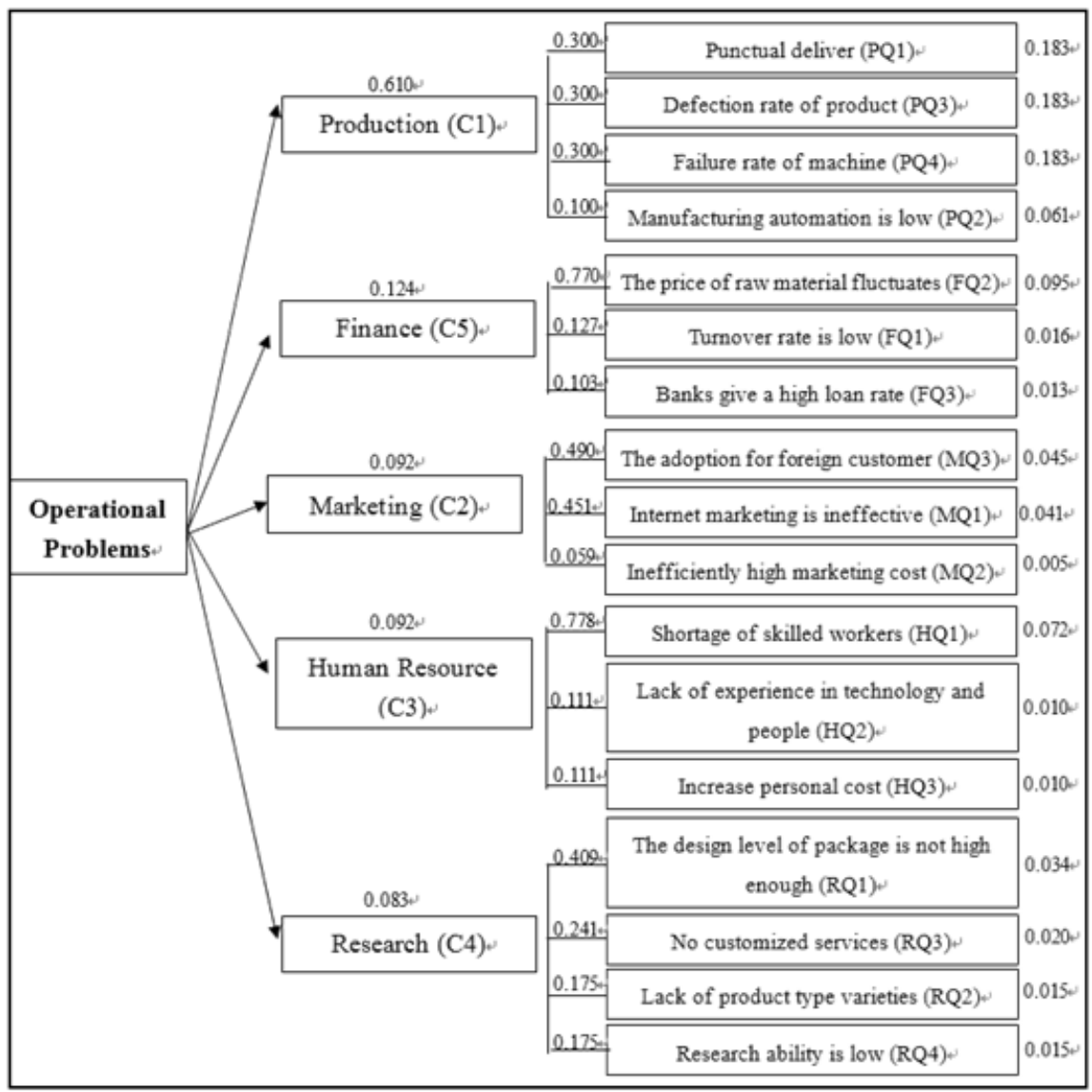

operational problems and action for solutions. These results are further calculated to get the relative weight to know which solution is more important.

Figure 4 shows that among 16 possible solutions to solve operational problems in the paper industry, Eliminate old machines to upgrade production efficiency (A3) is the most effective solution (14.77\%), followed by Hire young and outstanding people (A10) with $8.71 \%$, Provide complete training to upgrade employees' techniques (A13) with $8.26 \%$, Develop different qualities of papers to meet the market's demand (A7) with $8.14 \%$, Outsource other professional companies (A11) with $7.65 \%$, and so on. It indicates that management can focus on A3 more to solve operational problems, similarly for other solutions. Through this way, management may be able to work more effectively and efficiently because they know which solution has more influence in dealing with the problem. Thus, they will not waste their time to do other things.

There are some examples that the 16 possible solutions can solve the operational problems of each department. From A1 to A5, they can solve production problems. From A6 to A9, they can solve marketing problems. From A10 to A13, they can solve human resource and R\&D problems. From A14 to A16, they can solve finance problems. According to production problems, TQM is an effective method of managing an organization to improve its overall efficiency and performance. According to Zhang, Waszink, and Wijngaard (2000), the Chinese manufacturing industry started to implement TQM since 1978 while Chine still had inefficient effective quality management systems 
Figure 3.

\begin{tabular}{|c|c|c|c|c|c|c|c|c|c|c|c|c|c|c|c|c|}
\hline & A1 & A2 & $A 3$ & A4 & As & A6 & A7 & As & A9 & A10 & A11 & A12 & A13 & $\mathbf{A 1 4}$ & A15 & A16 \\
\hline $\begin{array}{l}\text { Implement logisties management } \\
\text { system(A1) }\end{array}$ & & $\mathrm{x}$ & $\mathrm{x}$ & $\mathbf{x}$ & $\mathrm{x}$ & & & $\mathrm{x}$ & $\mathrm{x}$ & & $\mathrm{x}$ & & & & & \\
\hline Put TQM imo prastice(A2) & $\mathrm{x}$ & & $\mathbf{x}$ & $\mathbf{x}$ & & & & & & & & & & & & \\
\hline \begin{tabular}{|l} 
Eliminate old machines to \\
producturtion efficiescos(A3)
\end{tabular} & $\mathbf{x}$ & $\mathrm{x}$ & & $\mathbf{x}$ & $\mathbf{x}$ & & & & $\mathrm{x}$ & $\mathrm{x}$ & & & $\mathbf{x}$ & & & \\
\hline Implement ERP electronic system(A) & $\mathbf{x}$ & $\mathrm{x}$ & $\mathbf{x}$ & & & & & & & $\mathrm{x}$ & & & $\mathrm{x}$ & & & \\
\hline |ncrease cussomers' satisfactiog(AS) & $\mathrm{x}$ & & $\mathbf{x}$ & & & & & $\mathrm{x}$ & $\mathrm{x}$ & & & & $\mathbf{x}$ & & & \\
\hline $\begin{array}{l}\begin{array}{l}\text { Increase advertisement and marketing } \\
\text { activity(A6) }\end{array} \\
\end{array}$ & & & & & & & $\mathrm{x}$ & & & & & $\mathrm{x}$ & $\mathrm{x}$ & & & \\
\hline \begin{tabular}{|l} 
Develop different qualities of papers \\
Do meet the murkers demand(A7)
\end{tabular} & & & & & & $\mathbf{x}$ & & & & & & & & $\mathbf{x}$ & $\mathrm{x}$ & $\mathrm{x}$ \\
\hline Upgrade service qualio(A\&) & $\mathrm{x}$ & & & & $\mathrm{x}$ & & & & $\mathrm{x}$ & $\mathrm{x}$ & & $\mathrm{x}$ & & & & \\
\hline $\begin{array}{l}\text { Participate more fairs to explore more } \\
\text { customers(A9) }\end{array}$ & $\mathrm{x}$ & & $\mathrm{x}$ & & $\mathrm{x}$ & & & $\mathrm{x}$ & & & & $\mathrm{x}$ & & & & \\
\hline \begin{tabular}{|l} 
Hire youmg and outseseding \\
people(AlO)
\end{tabular} & & & $\mathbf{x}$ & $\mathrm{x}$ & & & & $\mathrm{x}$ & & & $\mathrm{x}$ & $\mathrm{x}$ & $\mathrm{x}$ & & & \\
\hline 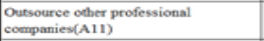 & $\mathrm{x}$ & & & & & & & & & $\mathrm{x}$ & & $\mathrm{x}$ & $\mathrm{x}$ & & & \\
\hline $\begin{array}{l}\text { Imternal rotation of compary to } \\
\text { cultivate all-roxad employees(A12) }\end{array}$ & & & & & & $\mathrm{x}$ & & $\mathrm{x}$ & $\mathrm{x}$ & $\mathrm{x}$ & $\mathbf{x}$ & & & & & \\
\hline $\begin{array}{l}\text { Provide complete training so upgrade } \\
\text { employees' techiquers(A13) }\end{array}$ & & & $\mathbf{x}$ & $\mathbf{x}$ & $\mathbf{x}$ & $\mathbf{x}$ & & & & $\mathrm{x}$ & $\mathbf{x}$ & & & & & \\
\hline $\begin{array}{l}\text { Massive procurement for } \\
\text { costdown(A14) }\end{array}$ & & & & & & & $\mathrm{x}$ & & & & & & & & $\mathbf{x}$ & $\mathrm{x}$ \\
\hline $\begin{array}{l}\begin{array}{l}\text { Strategic alliusces with other } \\
\text { companies(A15) }\end{array} \\
\end{array}$ & & & & & & & $\mathrm{x}$ & & & & & & & $\mathbf{x}$ & & $\mathrm{x}$ \\
\hline $\begin{array}{l}\text { Strive for more banks to lower the loan } \\
\text { rate(A16) }\end{array}$ & & & & & & & $\mathrm{x}$ & & & & & & & $\mathrm{x}$ & $\mathbf{x}$ & \\
\hline
\end{tabular}

Figure 4.

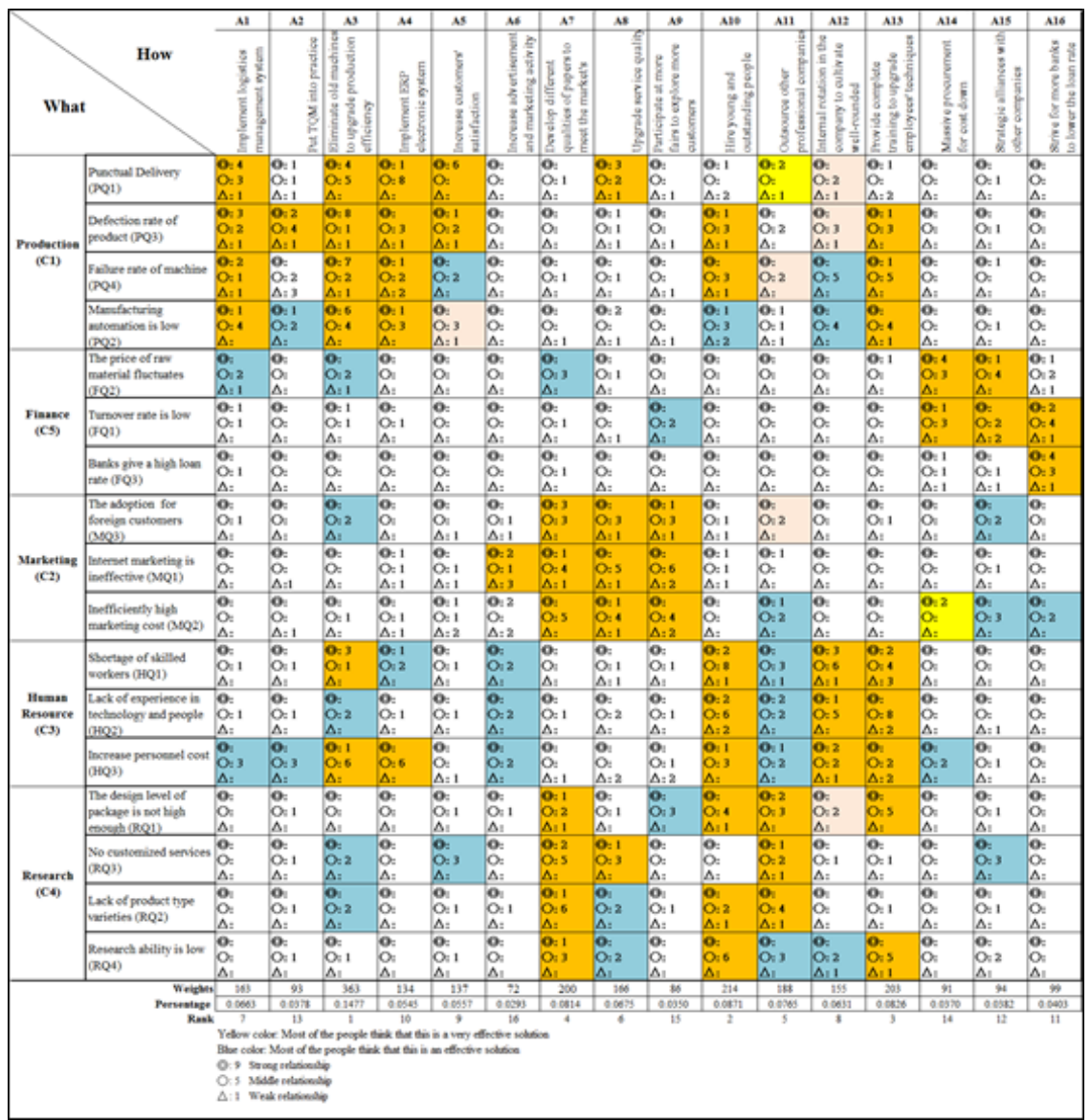


Figure 5.

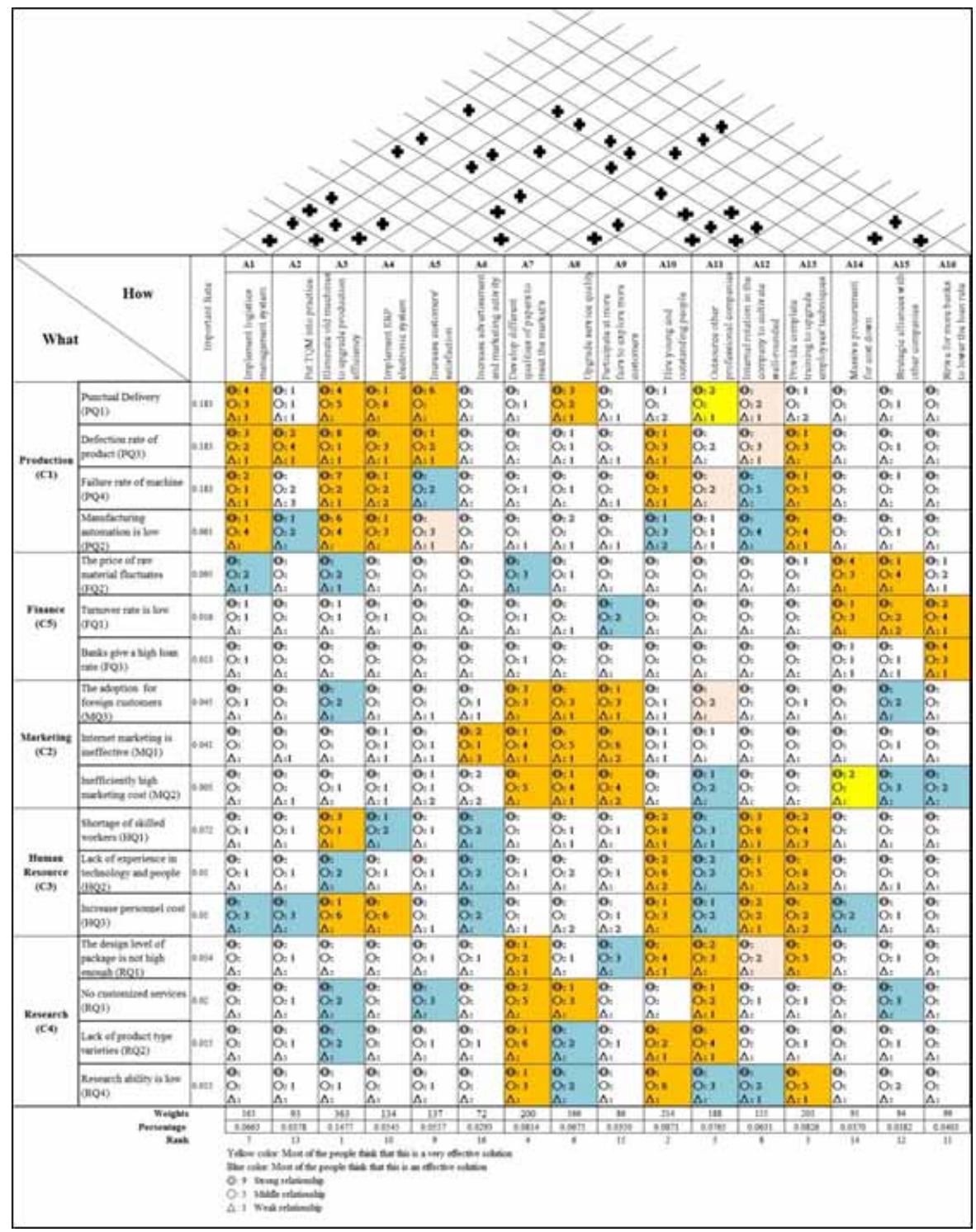

and applications at the business level. There has not been prominent progress in the beginning though Chinese government has made great efforts to urge companies to implement TQM to improve product quality. Afterward, the empirical data indicated that TQM implementation instrument is reliable and valid. It can also be used directly in other studies for different populations.

As to marketing problems, increasing advertising and marketing activities is critical to attract customers in the paper industry. According to Oladepo and Abimbola (2015), advertising is essential in the long run by making customers less price sensitive as well as by reducing the size of non-loyal segment. Hence, the importance of advertising and marketing has to be focused on. Price is not necessarily the most important though every manager in the paper industry wants to save the cost; however, maintaining a stable quality is a better way to run the business in the long run. As to human resource and $R \& D$ problems, outsourcing the professionals can save the cost and time of training new 
comers and sustain the stability of product. In addition, the internal rotation of an organization can effectively cultivate well-rounded employees. As to financial problems, strategic alliances with other companies can solve the operational problems. According to Gulati, Wohlgezongen and Zhelyazkov (2012), alliances are cooperative relationships driven by a logic of strategic resource needs and social resource opportunities. The resource such companies acquire through alliance could enable them to share costs or to differentiable technologies that outweigh alliance formation disadvantages. Therefore, a strategic alliance is not only suitable for financial problem but also suitable for other department problems.

\section{The House of Quality}

Finally, by combining the above results, this study built up the HOQ for operational problems and its solutions in the paper industry in Taiwan. The sign of roof part of Figure 5 indicates the positive or negative relationship between two actions. The plus sign means there is a positive relationship between action 1 and action 2. When you want to increase A1, you also need to increase A2. Meanwhile, the minus sign means there is a negative relationship between action 1 and action 2 . When you want to increase $\mathrm{A} 1$, you need to decrease $\mathrm{A} 2$.

Take the production and human resource department, for example, when a company wants to Eliminate old machines to upgrade production efficiency (A3), it also intends to Increase customers' satisfaction (A5). By upgrading production efficiency, the quality, price, and delivery time can be improved a lot; when the company wants to Hire young and outstanding people (A10), it also needs to Provide complete training to upgrade employees' technique (A13). It is because the company needs to have not only new skilled people, but also skilled current people. In addition, Figure 5 shows the HOQ of this study and the professional viewpoints of experts from the Taiwan paper industry.

\section{RESEARCH DISCUSSION}

This study focuses on capabilities part, which means how to shape the company's resource deployment and its decision-making process while providing it with the capacity to compete. By conducting QFD with experts and managers in the paper industry, the results of this study provide appropriate action for solutions to deal with operational problems. The solutions are derived based on the capacity of the company. Thus, the possibility of solving the operational problems is doable.

Based on the results of this study, several conclusions can be drawn as follows. Regarding the results of CIT, there are many operational problems and action solutions emerged through openended questionnaire. The results show that experts and managers address operational problems in production department as the most important problem that needs to get priority to be solved $(\mathrm{ev}=0.61)$. Production problems such as punctual delivery, defection rate of product, and failure rate of machine are the most crucial problem in the paper industry. This result is supported by previous studies of Miranda et al., (2010). In dealing with those problems, experts and managers agree that they need to improve the implementation of logistics management system (A1), eliminate old machine to upgrade production efficiency (A3), implement ERP electronic system (A4), and increase customer satisfaction (A5). These problems are very critical to be solved because when the delivery is not on-time, the production of the paper cannot be done. It means that there will be no activity in the company that further creates negative influence on company performance. Similarly, defection rate of product and failure rate of machine will make production activity become difficult. Besides, the product itself will have low quality. The second most crucial problem in the paper industry comes from finance department $(\mathrm{ev}=0.124)$. The price of raw material is getting expensive, and it gives the paper industry many financial problems (Mahmood \& Elliott, 2006). When the price of raw material is high, the company has to be very efficient in using it. Another issue is when the turnover rate of the company is low which indicate that company will have less money available. The high rate of bank loan also makes company difficult to get the money. Companies may have money from the banks, but it will 
be difficult for them to pay it back because the rate is too high. Thus, some companies choose not to borrow money from banks. As a consequence, they may have shortage financial situation. In order to solve these problems, managers suggest to ally strategically with other companies (A15) and strive for more banks to lower the loan rate (A16).

Furthermore, the problem in marketing department $(\mathrm{ev}=0.092)$ also needs to be considered. The results of this study show that the adoption for foreign customers is the problem needed to get more attention from the company. It is because the company may not be able to introduce the product to foreign customers if it cannot fulfill what foreign customers want (Lee, Kim \& Kwon, 2017). Besides,the company also needs to consider the tools in marketing context. The result of this study shows that ineffective internet marketing can also create problems in operational activity in the paper industry. Therefore, managers create possible solutions including developing different qualities of paper (A7), upgrade service quality (A8), take part in more fairs to explore more customers (A9), and increase advertisement and marketing activity (A6).

Moreover, in human resource department $(\mathrm{ev}=0.092)$, the shortage of skilled workers creates problems during operational activity. This result is consistent with (Kinda, 2010). When the workers lack skills, they will not be able to work in an effective and efficient way. They may waste time, waste the raw materials or other resources, and make many mistakes which further negatively impacts the product. Furthermore, workers with lack experience in technology can also inhibit operational activity in the paper industry. When the workers do not know how to use machine correctly, they may produce the product inefficiently. Besides, increasing personnel cost also creates problems in operational activity. High cost must be compensated by high quality of personnel so that the cost that has been spent will be worth it. Therefore, managers may decide to hire young and outstanding people (A10), outsource other professional companies (A11), internal rotation of company (A12), and provide complete training to upgrade employees' techniques (A13).

Finally, the least important but still need to be considered is the problem from R\&D department $(\mathrm{ev}=0.083)$. The design of the package that is not high as a result of low quality in R\&D department is the crucial problem needed to be solved. $R \& D$ department needs to understand the customers' needs and wants including the design of package. When they cannot do that, they will fail to satisfy customers which further leads to the company's negative effect. Similarly, when R\&D department does not improve its ability, they will not create new products so that the variety of the product will be low. In order to deal with these problems, managers need to improve their human resources and upgrade their services. Managers may hire young and outstanding people (A10), outsource other professional companies (A11), design different qualities of papers to meet the market's demand (A7), or upgrade service quality (A8).

\section{CONCLUSION}

\section{Conclusion}

The main objective of this study is to explore operational problems in the paper industry by using the CIT method and then utilizing the QFD and AHP method to find the effective solution actions for each problem. It can come up with conclusion that the most effective action to deal with operational problems is "eliminate old machine to upgrade production efficiency". It is consistent with Upadhye, Deshmukh, and Garg's study (2010). The result makes sense because the most crucial problem comes out from production department. Thus, the action regarding production activity needs to get more attention. By eliminating old machine, the company will be able to produce more and perform more effectively and efficiently. Furthermore, changing the machine with the new one is believed to solve the problem related to foreign customers. It is because foreign customers may have different preferences with local customers, thus the company needs to adjust their machine with one that is flexible to be used and provides many different features. Moreover, this action also can minimize the problem of shortage personnel skill. It is because by having new technology, the company can 
replace human resources with machines. Thus, the company not only can reduce shortage of skilled employees but also the labor cost. In the R\&D department, this action is also useful for creating a variety of product because new technology provides many features to create it. The second of the most effective action for solutions is "hire young and outstanding people." This action is explicitly needed for human resource department. Skilled personnel will produce good performance which further creates good quality of products. Therefore, finding and organizing human resource is significant for the company. Furthermore, the other action that needs to be done is "providing complete training to upgrade employees' techniques." The company will have skilled employees in each department by hiring competent employees and providing them with a complete training. The result of this study provides the other solutions that the company may take to solve operational problems. Managers may take the most effective solution first, followed by other solutions to minimize the failure and maximize the possibility of dealing with certain operational problems.

For the correlation among action for solution shown in the roof of HOQ, this study concludes as follows. From the experts' and managers' point of view in solving operational problems, the company may need to combine several actions. The plus sign on the roof means action one and action two have positive relationships. When action one increases, action two also has to increase. Contrarily, the minus sign on the roof means action one and action two have negative relationship. When action one increases, action two has to decrease. Take the human resource department, for example, when the company wants to "hire young and outstanding people," it also needs to "provide complete training to upgrade employees' technique." It is because the company needs to have not only new skilled employees, but also the current one. Besides, these new people can also learn about the company from the training. Take the production department for another example, when the company wants to "eliminate old machines to upgrade production efficiency", it also intends to "increase customers" satisfaction". By upgrading production efficiency, the quality, price, and delivery time can be improved a lot. Consequently, the customers' satisfaction will increase. Thus, it is important to do both of those actions at the same time. The roof of HOQ in this study is useful for management to consider not only in one action, but also the other possible action for solutions.

\section{Managerial Implication}

Based on the results of this study, several managerial implications can be drawn as follows. First of all, the major purpose of this study is to explore operational problem and identify the level of importance of those problems from experts' and managers' point of view. The results show that the most crucial problems in operational activities come from production department which are "punctual delivery," "defection rate of product," and "failure rate of machine." Based on that, paper companies should put more effort in solving those problems rather than other problems in operational activity. Managers can make a list based on the important rate on HOQ, which problems have to be solved first followed by other problems. They should do this to avoid wasting time and resources for the problems that actually do not have too much influence on the company.

Secondly, managers need to choose the most effective solution for solving operational problems. Based on the roof of HOQ, managers can also make a list on which action they can take first and give more effort to implement it. Through that way, managers can not only solve the problems, but also improve their quality in operational activity. Besides, since there is also a possibility that managers need to combine more than one action to solve the problems, they need to consider other actions when they want to implement a particular action. Thus, managers should think in broader view when they decide to choose a certain action.

Finally, by understanding the relational matrix on $\mathrm{HOQ}$, managers will be able to understand which action is suitable for a particular problem. There may be more than one action for 1 problem. Thus, managers should consider the overall actions instead of an individual one. Managers should also think about the available resources they have, not only about raw materials or such, but also financial 
and human resources. Managers cannot choose all actions when they actually do not have enough resources. Therefore, managers should really consider the best action among several alternative actions.

\section{Limitation and Suggestions for Future Research}

As with all studies, this research has notable limitations that may be investigated in the future research. Firstly, the results of this study and its implication were obtained from the paper industry in Taiwan; hence, when it applies in other countries, the results may be different. Therefore, future study may conduct a research that not only for Taiwanese experts and managers, but also for other countries. Through this way, future research may find another important factor that influences on both operational problem and action for solutions. Secondly, this study focused on the solving of operational problems in the paper industry. Future study may not only focus on solving the operational problems, but also improving the effectiveness of operational activity. It will give more contribution to the company. Furthermore, the HOQ in this study only focuses on the internal company. Thus, future study may extend the investigation on how competitors deal with similar operational problems. By doing benchmarking, the company will have more knowledge to solve operational problems not only from the internal company, but also from competitors. Finally, each department has their own problems that need solution. Future research may focus on each problem and provide more sophisticated solution. 


\section{REFERENCES}

Adler-Milstein, J., Singer, S. J., \& Toffel, M. W. (2009). Operational failures and problem solving: an empirical study of incident reporting. Harvard Business School Technology \& Operations Mgt. Unit Working Paper, (10-017).

Amihud, Y., \& Lev, B. (1981). Risk reduction as a managerial motive for conglomerate mergers. The Bell Journal of Economics, 12(2), 605-617. doi:10.2307/3003575

Brunton, M. A., \& Jeffrey, L. M. (2010). Using the critical incident technique for triangulation and elaboration of communication management competencies. Journal of Vocational Education and Training, 62(3), 239-255. doi:10.1080/13636820.2010.499475

Chan, L. K., \& Wu, M. L. (2002). Quality function deployment: A literature review. European Journal of Operational Research, 143(3), 463-497. doi:10.1016/S0377-2217(02)00178-9

Civi, E. (2000). Knowledge management as a competitive asset: A review. Marketing Intelligence \& Planning, 18(4), 166-174. doi:10.1108/02634500010333280

Dahal, R. P., Henderson, J. E., \& Munn, I. A. (2015). Forest products industry size and economic multipliers in the US South. Forest Products Journal, 65(7), 372-380. doi:10.13073/FPJ-D-14-00083

Figueira, G., Santos, M. O., \& Almada-Lobo, B. (2013). A hybrid VNS approach for the short-term production planning and scheduling: A case study in the pulp and paper industry. Computers \& Operations Research, 40(7), 1804-1818. doi:10.1016/j.cor.2013.01.015

Gavrilescu, D., Puitel, A. C., Dutuc, G., \& Craciun, G. (2012). Environmental impact of pulp and paper mills. Environmental Engineering and Management Journal, 11(1), 81-85. doi:10.30638/eemj.2012.012

Ghosal, V., \& Nair-Reichert, U. (2009). Investments in modernization, innovation and gains in productivity: Evidence from firms in the global paper industry. Research Policy, 38(3), 536-547. doi:10.1016/j. respol.2008.10.010

Gilboa, S., Shirom, A., Fried, Y., \& Cooper, C. (2008). A meta-analysis of work demand stressors and job performance: Examining main and moderating effects. Personnel Psychology, 61(2), 227-271. doi:10.1111/ j.1744-6570.2008.00113.x

Gulati, R., Wohlgezogen, F., \& Zhelyazkov, P. (2012). The two facets of collaboration: Cooperation and coordination in strategic alliances. The Academy of Management Annals, 6(1), 531-583. doi:10.5465/194165 20.2012.691646

Hou, Y. C. (2009). A Case Study of Service Recovery and Customer Repurchases for the Paper Industry in Southern Taiwan (Master). NCKU.

Howe-Walsh, L., \& Schyns, B. (2010). Self-initiated expatriation: Implications for HRM. International Journal of Human Resource Management, 21(2), 260-273. doi:10.1080/09585190903509571

Huan, H., Yongyuan, M., Sheng, Z., \& Qinchao, D. (2017). Characteristics of knowledge, people engaged in knowledge transfer and knowledge stickiness: Evidence from Chinese R\&D team. Journal of Knowledge Management, 21(6), 1559-1579. doi:10.1108/JKM-02-2017-0054

Huselid, M. A. (1995). The impact of human resource management practices on turnover, productivity, and corporate financial performance. Academy of Management Journal, 38(3), 635-672.

Jauhar, S. K., Pant, M., \& Abraham, A. (2014). A novel approach for sustainable supplier selection using differential evolution: a case on pulp and paper industry. In Intelligent Data analysis and its Applications (Vol. 2, pp. 105-117). Springer. doi:10.1007/978-3-319-07773-4_11

Keller, K. L. (2017). Managing the growth tradeoff: Challenges and opportunities in luxury branding. In Advances in luxury brand management (pp. 179-198). Palgrave Macmillan. doi:10.1007/978-3-319-51127-6_9

Kinda, T. (2010). Investment climate and FDI in developing countries: Firm-level evidence. World Development, 38(4), 498-513. doi:10.1016/j.worlddev.2009.12.001 
Kjellberg, H., Azimont, F., \& Reid, E. (2015). Market innovation processes: Balancing stability and change. Industrial Marketing Management, 44, 4-12. doi:10.1016/j.indmarman.2014.10.002

Lee, J., Kim, S. J., \& Kwon, I. (2017). Corporate social responsibility as a strategic means to attract foreign investment: Evidence from Korea. Sustainability, 9(11), 2121. doi:10.3390/su9112121

Lin, B., \& Zheng, Q. (2017). Energy efficiency evolution of China's paper industry. Journal of Cleaner Production, 140, 1105-1117. doi:10.1016/j.jclepro.2016.10.059

Mahmood, T., \& Elliott, A. (2006). A review of secondary sludge reduction technologies for the pulp and paper industry. Water Research, 40(11), 2093-2112. doi:10.1016/j.watres.2006.04.001 PMID:16701789

Miranda, R., Bobu, E., Grossman, H., Stawicki, B., \& Blanco, A. (2010). Factors influencing a higher use of recovered paper in the European paper industry. Cellulose Chemistry and Technology, 44(10), 419.

Oladepo, O. I., \& Abimbola, O. S. (2015). The influence of brand image and promotional mix on consumer buying decision-a study of beverage consumers in Lagos State, Nigeria. British Journal of Marketing Studies, 3(4), 97-109.

Pakdil, F., Işın, F. B., \& Genç, H. (2012). A quality function deployment application using qualitative and quantitative analysis in after sales services. Total Quality Management \& Business Excellence, 23(11-12), 1397-1411. doi:10.1080/14783363.2012.715797

Paryani, K., Masoudi, A., \& Cudney, E. A. (2010). QFD application in the hospitality industry: A hotel case study. The Quality Management Journal, 17(1), 7-28. doi:10.1080/10686967.2010.11918258

Saaty, T. L. (2004). Decision making — The analytic hierarchy and network processes (AHP/ANP). Journal of Systems Science and Systems Engineering, 13(1), 1-35. doi:10.1007/s11518-006-0151-5

Sharma, M. J., Moon, I., \& Bae, H. (2008). Analytic hierarchy process to assess and optimize distribution network. Applied Mathematics and Computation, 202(1), 256-265. doi:10.1016/j.amc.2008.02.008

Smith, K. G., Ferrier, W. J., \& Ndofor, H. (2005). Competitive Dynamics Research: Critique and Future Directions. The Blackwell Handbook of Strategic Management, 309-354.

Stirn, L. Z. (2006). Integrating the fuzzy analytic hierarchy process with dynamic programming approach for determining the optimal forest management decisions. Ecological Modelling, 194(1-3), 296-305. doi:10.1016/j. ecolmodel.2005.10.023

Temponi, C., Yen, J., \& Tiao, W. A. (1999). House of quality: A fuzzy logic-based requirements analysis. European Journal of Operational Research, 117(2), 340-354. doi:10.1016/S0377-2217(98)00275-6

Tucker, A. L. (2004). The impact of operational failures on hospital nurses and their patients. Journal of Operations Management, 22(2), 151-169.

Upadhye, N., Deshmukh, S. G., \& Garg, S. (2010). Lean manufacturing system for medium size manufacturing enterprises: An Indian case. International Journal of Management Science and Engineering Management, 5(5), 362-375. doi:10.1080/17509653.2010.10671127

Zhang, Z., Waszink, A. B., \& Wijngaard, J. (2000). An instrument for measuring TQM implementation for Chinese manufacturing companies. International Journal of Quality \& Reliability Management, 17(7), 730-755. doi: $10.1108 / 02656710010315247$ 
Chai Wei Lo is the chairman of An Jong Enterprise company in Taiwan. He graduated from Institute of International Management, National Cheng Kung University, Taiwan (R.O.C.).

Ying Kai Liao is the Associate Professor of the Program of International Business at Nanhua University, Taiwan. Her teaching and research interest are in the areas of brand management, marketing strategy, social media marketing and new product development management. Her research has been published in Asia Pacific Marketing Review, International Journal of Hospitality Management, Project Management Journal and Computers in Human Behavior.

Giang Nu To Truong is currently studying the PhD in Business Administration at College of Management, Nanhua University, Taiwan. Her teaching and research interests are in the areas of tourism, hospitality, business, and marketing.

Phuong Minh Binh Nguyen is currently teaching at Faculty of Tourism, Van Lang University, Ho Chi Minh City, Vietnam. His research interests are in the areas of tourism, hospitality, management, and marketing.

Wann Yih Wu is a Chair Professor in Nanhua University, Taiwan. His teaching and research interests are in the areas of brand management, marketing strategy, and management science. His research has been published in International Journal of Hospitality Management, Project Management Journal, International Journal of Consumer Studies, Industrial Management and Data Systems, and others. 